\section{Tinta indeleble. Guillermo Cano vida y obra}

\author{
Fundación Guillermo Cano y Aguilar \\ Autores: Marisol Cano Busquets \\ Jorge Cardona Alzate \\ Carlos Mario Correa Soto \\ Maryluz Vallejo Mejía
}

Año: 2012

Número de páginas: 650

Por: Diana Ximena Bejarano B.

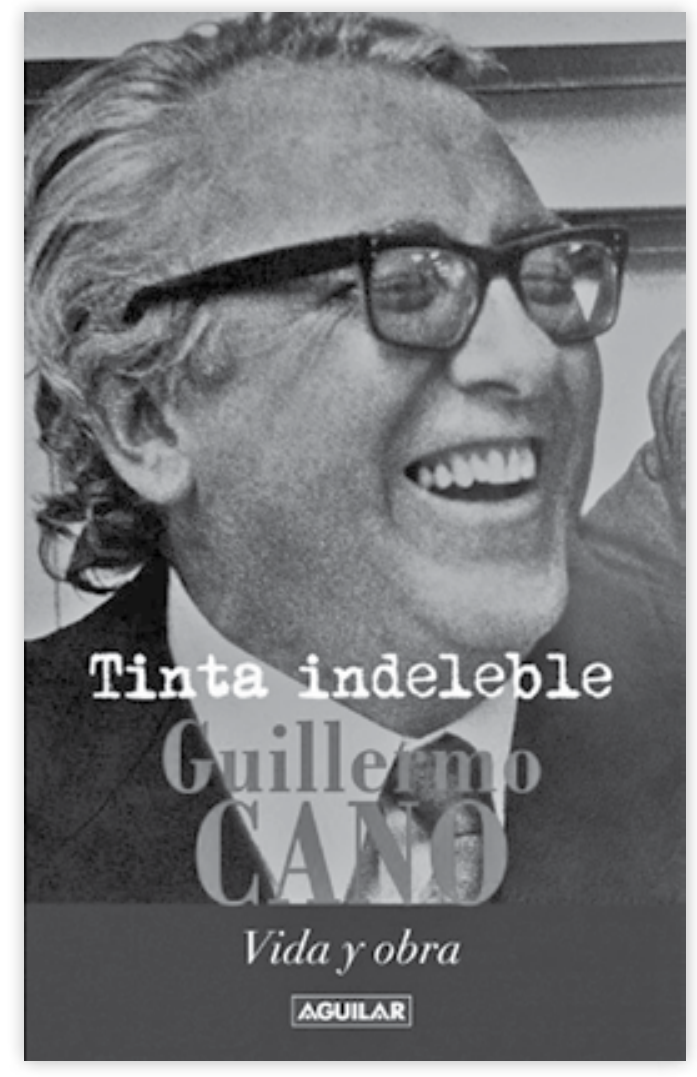

conservadora en represalia por el asesinato de cinco de sus compañeros. Fue uno de los peores ataques sufridos por el diario durante el cual los revoltosos invadieron la sede del periódico y destruyeron cuanto objeto encontraban a su paso. Máquinas de escribir, grabadoras, archivos y todo lo necesario para el ejercicio del periodismo quedó inservible mientras las últimas ediciones eran consumidas por las llamas. Fue ese mismo día cuando se tomó la decisión de nombrar a Guillermo Cano director del diario junto a su padre Gabriel.

A manera de flashback el libro remonta la historia del ilustre periodista a sus primeros años de vida. Proveniente de San Pedro, Antioquia, la familia se establece en Bogotá cuando Guillermo ni siquiera había nacido. Su niñez transcurre entre estas dos regiones en medio de la tranquilidad y la unión familiar con navidades plenas de regocijo y felicidad, sentimientos que años más tarde sembró en su propio hogar. Rodeado de buenos amigos Guillermo Cano tuvo la oportunidad de estudiar en el Gimnasio Moderno, uno de los mejores colegios de Bogotá. El libro destaca que don Guillermo se caracterizó por su sencillez y por querer

DIANA XIMENA BEJARANO B. Candidata a Máster en Comunicación Digital, Universidad Pontificia Bolivariana de Medellín. Especialista en Administración de Negocios, Universidad de San Buenaventura Cali. Comunicadora Social-Periodista, Universidad Autónoma de Occidente. Asistente revista Guillermo de Ockham Universidad de San Buenaventura Cali 
aprenderlo todo acerca del periodismo, incluso sus oficios más humildes y operativos: "[...] había llegado a los 13 años a apoyar la dura tarea de fundir las barras de metal para los linotipos". Una vez graduado de bachiller, su padre lo introduce en el mundo del periodismo donde fortaleció sus habilidades escriturales. Se inició en la reportería con una de sus pasiones: la tauromaquia, y publicó sus primeras crónicas en la sección "La fiesta brava" las cuales firmaba con el seudónimo de Conchito e impresionaba al lector con sus narraciones:

- -Soy torero porque sí! Porque siento deseos de torear: porque me gusta la fiesta de los toros; porque desde muy pequeño he vivido en este ambiente caldeado de toreros, toros, discusiones apasionadas, cornadas, críticas, alabanzas, en fin, en toros.

Así me habló Luis Ospina, "El bizco", sentado en el Café Colombia, pocas horas después de haber salido en hombros, triunfalmente, por la puerta de la Plaza de Santamaría. En amena charla, Luis Ospina cuenta su carrera taurina, iniciada desde muy pequeño, cerca de su barrio de Las Cruces, donde nació y donde piensa morir.

Su prosa le abrió las puertas para formarse al lado de periodistas como Antonio Rueda, José Salgar y Darío Bautista y a su vez compartir las tareas informativas y su "don de cazatalentos" -como lo mencionan los autores-con colegas que luego se convertirían en grandes exponentes de la literatura, como Gabriel García Márquez (quien fue reportero del diario y en 1955 se dio a conocer con una historia que luego se convertiría en una de sus primeras obras literarias: Relato de un náufrago), Jorge Padilla, Felipe González Toledo, Germán Pinzón y Manuel Mejía Vallejo.

El segundo capítulo titulado "El Sentido de lo profundo" se concibe como un texto narrativo y formativo para periodistas de acuerdo con el estilo desarrollado por Guillermo Cano, el cual aprendió de manera empírica, pues en su época no existían las facultades de periodismo. Se recogen aquí sus principales enseñanzas para la escritura de la crónica, como la técnica narrativa, el manejo del punto de vista, el desarrollo temporal del suceso y el uso de los personajes. Se habla del famoso tráiler referente a las escenas que deben componerla y a lo definido por Cano como cocktail, que no era más que "una mezcla de noticias, situaciones y curiosidades redactadas en un lenguaje sencillo y ameno".

Este primer bloque recoge tanto los mejores momentos de Guillermo Cano como los peores en su entorno familiar, su círculo de amigos y su ambiente profesional. Retrata los tiempos amargos de la censura y cómo su perseverancia y voluntad de lucha sirvieron para sacar adelante el diario. Los autores resaltan su gestión en los momentos más críticos del Frente Nacional, la llegada de los hijos y su famosa "Libreta de apuntes" por la cual es sumamente recordado. Culmina con el relato de los hechos trágicos del 17 de diciembre de 1986 cuando luego de terminar su último editorial, irónicamente titulado Navidades negras, fue vilmente asesinado a las afueras del periódico por las fuerzas oscuras del narcotráfico.

La segunda parte del libro es una antología de textos narrativos y crónicas y en ella se transcriben sus famosas crónicas taurinas, deportivas y de ciudad y se delinea su faceta de reportero, claro ejemplo de madurez periodística. Algunas son tan humanas que cualquier ciudadano podía verse reflejado en ellas. Su sentir era el ingrediente perfecto para acercar a sus lectores:

Y de Lisboa pasamos a Roma. Fuimos llevados al Hotel Excelsior considerado con justicia como uno de los más lujosos de toda Europa. Nuestra primera inspección, antes que la del cuarto, fue penetrar ansiosamente al bańo, en busca de la regadera. $Y$ la había, existía, brillante, tentadora sobre una tina blanca, como en cualquier baño de Bogotá. No pudimos contener un grito de victoria, y rápidamente nos desvestimos para colocarnos bajo los chorros picantes del agua corriente y jabonarnos... Los ojos se levantaron hacia la regadera que coqueta y atractiva, nos invitaba a colocarnos debajo de ella. Pero por los huequitos que nos habían embrujado instantes antes no salió ni una gota de agua...

Definitivamente lo que ocurría era que la regadera no funcionaba...

Entonces lo comprendimos todo....La regadera estaba tapada...Tapada por el agua caliza de Roma... Tapada porque, desde hacía muchos años, nadie la había usado...Y tomamos un alfiler, pedimos limón, para sorpresa de los criados, y nos dedicamos con la paciencia que solo puede tener quien fervientemente desea una cosa, hueco por hueco, a destapar la regadera... 
Al final de esta segunda parte nos topamos con Bitácora sin pierde, fragmento que pretende resaltar las bondades de la "Libreta de Apuntes" -su sección más característica- y los siete temas que nunca podían faltar: violencia y paz; derechos humanos; política; narcotráfico; corrupción; libertad de prensa y responsabilidad social; y vida cotidiana (seres queridos, gustos literarios y asuntos varios).

La última parte de la obra está compuesta por crónicas de opinión, columnas y editoriales, escritos cargados de crítica y reproches a la clase política y por los cuales tanto él como su familia y el diario sufrieron rabiosos ataques. Eran espacios dedicados a divulgar la verdad, a defender los intereses sociales y a sacar a la luz pública las maniobras de corruptos que pretendían entorpecer la democracia colombiana:

Cuántos sobresaltos se le habrían podido evitar a este lindo país colombiano si quienes en el momento tenían en sus manos y en sus decisiones el poder suficiente para detener la enorme bola de nieve de la inmoralidad que comenzaba a formarse y a rodar implacablemente, impulsada por el insólito caso de las multimillonarias defraudaciones de los fondos de inversión Bolivariano y Grancolombiano -ambos subsidiarios del grupo todopoderoso que se había convertido en el coco para todo el mundo, comenzando por las más altas autoridades de la República-, hubieran actuado pronta y cumplidamente.

No se tuvieron, sin embargo, ni el valor ni el coraje ni la entereza de enfrentar a los defraudadores que iniciaban apenas su carrera delictuosa. Y de allí se desprende-no le quepa la menor duda-la catástrofe en que se sumió el sistema financiero colombiano en los años pasados, hasta postrarlo en el más alto grado de desconfianza pública de que se tenga noticia en este país.

Este era el estilo de Guillermo Cano para llamar a la conciencia y a la aplicación de los valores morales y éticos de quienes manejaban los recursos de los ciudadanos. Sin embargo, sus columnas y editoriales también reflejaron su admiración por aquellos amigos y colegas que contribuyeron a su formación como periodista y a forjar en su conciencia el deber de aplicar durante su larga carrera los principios éticos para ejercer un verdadero periodismo, lo cual hizo sin vacilar durante sus 42 años de carrera. La invitación es, entonces, para que los amantes de la escritura y en particular de la crónica periodística se enriquezcan de forma amena con las mejores enseńanzas de uno de los precursores del periodismo colombiano. 